\title{
Culture Contact, Cross-cultural Communication and Mental Adaptation _an Empirical Analysis Based on 273 International Students in China from Thailand, Vietnam and Laos
}

\author{
Lei Zhang
}

School of Tourism and Geographical Science, Yunnan Normal University, Kunming, 650500, China

Keywords: International students, Cross-cultural communication, Mental adaptation

\begin{abstract}
This research utilizes mental adaptation scales (Self-rating depression scale) to investigate and research on cross-cultural mental adaptation of 273 international students in China from Thailand, Vietnam and Laos. In order to offer referential research results to adjust and improve oversea students' teaching methods, this paper analyzes and discusses the cross-cultural mental adaptation situation of international students in China from three other countries by using statistical approaches like factor analysis and variance analysis.
\end{abstract}

\section{Introduction}

As common subjects of cross-cultural communication, international students are going through psychological recovery and social culture studies. Under the inspiration of "culture shock", western cross-cultural communication researchers set international students as research objects and made empirical tests on many theoretical assumptions, among which the most representative ones are Lysgaard's “U shape curve” and Gullahorn's "W shape curve” Because of the difference in origins, cultural background and learning motivation, the study of international students' cross-cultural mental adaptation problems is of great practical significance.

\section{Research design}

Research tools. The first part of investigation in this questionnaire is demographic statistical information of international students in China, covering 10 items including gender, age, nationality, oversea study time, learning hierarchy, major, overseas experience, comprehension degree of China, comprehension degree of colleges and Chinese level. The second part of investigation in this questionnaire is mental adaptation situation of international students in China. It adopts the commonly-used Self-Rating Depression Scale (Zung 1965) with 20 items. The end of the questionnaire includes an item that research on social support situation of international students in China.

Reliability and validity of questionnaires. According to the calculation, the interior reliability index - Cronbach's Alpha coefficients are larger than 0.90, which reflects good reliability. The coefficients of Kaiser-Meyer-Olkin are larger than 0.50, and the significance probability of Bartlett Chi-square statistic value is 0.000 , proving that the structure validity of the scale is reasonable.

Investigation implement. This research selects international students in China from Thailand, Vietnam and Laos in Yunnan Normal University as research objects. Yunnan Normal University is one university which has intense international students of Southeast Asia. International students from Thailand, Vietnam and Laos are representative in education aspects. The investigation result of the questionnaire is analyzed by SPSS17.0.

Sample structure. This research analyzes the demographic information of 273 international students from Thailand, Vietnam and Laos. Due to limited space, this paper mainly presents the investigation result of 5 items, including gender, age, studying time, learning hierarchy and major. The testers include 95 Thai, 90 Vietnamese and 88 Laotians. The proportion of Thai males is the 
lowest. The gender structural difference of Vietnam and Laos is relatively small, which the female Vietnamese are more and male Laotians are more. The average age is almost the same in these three countries (21-22 years old).

\section{Result and analysis}

The Self-Rating Depression Scale (Zung 1965) adopted by research institutions includes Likert's four-degree scale with 20 items, which grades testers' direct feeling by using "never ", "sometimes", "frequently" and "always". The values are four, three, two, one, respectively, with the total mark 80 points. The higher score a tester gets, the higher degree of depression is. Researchers make further procession of the scores and reach the depression standard index. The calculation method is that the depression standard index is score dividing the total score. The evaluation criteria are: if the index is not more than 0.50 , there are no depressive symptoms. If the index is between 0.50 and 0.60 , it is minor depression. If the index is between 0.50 and 0.60 , it is minor depression. If the index is between 0.50 and 0.60 , it is minor depression. If the index is between 0.60 and 0.70 , it is moderate depression. If the index is over 0.70 , it is severe depression.

Factor analysis. According to the calculation, there are 7 factors whose characteristic roots are larger than 1 . The interpretation rate of accumulative variance is $63.184 \%$. According to the evaluation criterion of absolute value no less than 0.5 , the first factor integrates 6 original variables whose loads are no less than 0.524 , which are item 1, 9, 11, 12, 16 and 17 . The second factor integrates 3 original variables whose loads are no less than 0.583 , which are item 6,14 and 18 . The third factor integrates 2 original variables whose loads are no less than 0.673 , which are item 3 and 4 . The fourth factor integrates 3 original variables whose loads are no less than 0.611 , which are item 13 , 15 and 19. The fifth factor integrates 1 original variable whose load is no less than 0.767 , which is item 10 . The sixth factor integrates 3 original variables whose loads are no less than 0.521 , which are item 1, 5 and 8 . The seventh factor integrates 2 original variables whose loads are no less than 0.623 , which are item 2 and 20.

According to the calculation, there are 7 factors whose characteristic roots are larger than 1 . The interpretation rate of accumulative variance is $62.735 \%$. According to the evaluation criterion of absolute value no less than 0.5 , the first factor integrates 7 original variables whose loads are no less than 0.530 , which are item 2, 6, 11, 14, 17, 18 and 20. The second factor integrates 3 original variables whose loads are no less than 0.667 , which are item 7,8 and 9 . The third factor integrates 3 original variables whose loads are no less than 0.532 , which are item 12,15 and 16 . The fourth factor integrates 1 original variable whose load is no less than 0.832 , which is item 3 . The fifth factor integrates 1 original variable whose load is no less than 0.800 , which is item 1 . The sixth factor integrates 2 original variables whose loads are no less than 0.592 , which are item 5 and 13 . The seventh factor integrates 1 original variable whose load is no less than 0.809 , which is item 19 .

According to the calculation, there are 6 factors whose characteristic roots are larger than 1 . The interpretation rate of accumulative variance is $62.255 \%$. According to the evaluation criterion of absolute value no less than 0.5 , the first factor integrates 6 original variables whose loads are no less than 0.622 , which are item $11,14,16,17,18$ and 20 . The second factor integrates 4 original variables whose loads are no less than 0.510 , which are item 2, 5, 6 and 7. The third factor integrates 4 original variables whose loads are no less than 0.520 , which are item $1,8,9$ and 10 . The fourth factor integrates 3 original variables whose loads are no less than 0.512 , which are item 7,12 and 13 . The fifth factor integrates 2 original variables whose loads are no less than 0.607 , which are item 4 and 15.The sixth factor integrates 1 original variable whose load is no less than 0.882 , which is item 3 .

Difference analysis. Researchers use variance analysis method to test the difference of mental adaptation of these three countries. The results are as follows:

According to the test, China's Thai students' mental adaptation situation has notable difference in different age. The age of testers is notably related to the depression index, meaning that the larger the age is, the level of depression is enhanced. 
According to the test, Vietnamese students have notable difference in aspects of age, learning hierarchy, major. The age of testers has notable negative correlation with depression index. The younger the tester, the lower degree the depression index is. It indicates that the self-adaptation ability of depression is improved with age. The value of $\mathrm{F}$ in the variance test of learning hierarchy is 3.266. The concomitant probability is 0.010 , which is less than the significance level 0.05 . It rejects null hypothesis, meaning that there is distinct difference between at least one group and 5 other groups or there is notable difference among 6 groups. The value of $\mathrm{F}$ of major's variance test is 0.063 . It is larger than the significance level 0.05 , indicating that null hypothesis is acceptable and there is no notable difference among the three groups. After multiple comparisons, we find that there is notable difference in mental adaptation between the first group (Chinese major) and the second group (humanities and social sciences major).

According to the test, Laotian students have notable difference in aspects of studying time. The value of $\mathrm{F}$ in the variance test is 3.371 . The concomitant probability is 0.013 , which is less than the significance level 0.05 . It rejects null hypothesis, meaning that there is distinct difference between at least one group and 4 other groups or there is notable difference among 5 groups. After multiple comparisons, we find that there is notable difference in mental adaptation between the first group (1 to 8 months) and the second group (7-12 months), the second group (7-12 months) and the third group (13-24 months), the second group (7-12 months) and the fourth group (25-36 months), the second group (7-12 months) and the fifth group (more than 36 months). There is no difference among other groups. It proves that whether the time for studying abroad is within a year or over a year is an important phase of changes of mental adaptation situations.

Mental adaptation and social support. According to the statistics, 43.8\% Thai testers seek for help from families and friends if they have bad mental impression. 24\% Thai testers find help from their Chinese friends. 6.3\% Thai testers find help from other international students. 2.1\% Thai testers choose their Chinese teachers and the rest $16.7 \%$ haven't taken a stand.

According to the statistics, 54.4\% Vietnamese seek for help from families and friends if they have bad mental impression. 16.7\% Vietnamese choose Chinese friends for help. 5.6\% choose their Chinese teachers and $1.1 \%$ find help from other foreign students.

According to the statistics, 53.4\% Laotian testers seek for help from families and friends if they have bad mental impression. 10.2\% testers find help from their Chinese friends. $4.5 \%$ testers find help from other international students. 9.1\% seek for help from Laos in China. No one seeks for help from Chinese teachers and $21.6 \%$ haven't taken a stand.

Comparison of mental adaptation situations. According to statistics, the Pearson's correlation coefficient between depression index and overseas studying index of Thai students is 0.052. The value of $P$ is 0.619 , which is larger than the significance level 0.05 , meaning that the relationship is not notable. The Pearson's correlation coefficient between depression index and overseas studying index of Vietnamese students is 0.198 . The value of $\mathrm{P}$ is 0.062 , which is larger than the significance level 0.05 , meaning that the relationship is not notable. The Pearson's correlation coefficient between depression index and overseas studying index of Thai students is 0.259 . The value of $\mathrm{P}$ is 0.015 , which is smaller than the significance level 0.05 , meaning that the relationship is extremely notable and the depression degree is higher if the motivation to study abroad is stronger. 
Table 1. Population distribution of mental adaptation situations of international students in China from Thailand, Vietnam and Laos

\begin{tabular}{|c|c|c|c|c|c|c|}
\hline Nationality & & $\mathrm{N}$ & $\begin{array}{l}\text { Minimu } \\
\mathrm{m}\end{array}$ & $\begin{array}{l}\text { Maximu } \\
\mathrm{m}\end{array}$ & Mean & $\begin{array}{l}\text { Standar } \\
\mathrm{d} \\
\text { deviatio } \\
\mathrm{n}\end{array}$ \\
\hline \multirow[t]{2}{*}{ Thailand } & $\begin{array}{l}\text { Total mark of } \\
\text { mental } \\
\text { adaptation }\end{array}$ & 95 & 34 & 55 & 43.40 & 4.718 \\
\hline & $\begin{array}{l}\text { Depression } \\
\text { index }\end{array}$ & 95 & .4250 & .6875 & $\begin{array}{l}.54250 \\
0\end{array}$ & $\begin{array}{l}.058980 \\
7\end{array}$ \\
\hline \multirow[t]{2}{*}{ Vietnam } & $\begin{array}{l}\text { Total mark of } \\
\text { mental } \\
\text { adaptation }\end{array}$ & 90 & 20.00 & 52.00 & $\begin{array}{l}42.855 \\
6\end{array}$ & 5.80306 \\
\hline & $\begin{array}{l}\text { Depression } \\
\text { index }\end{array}$ & 90 & .25 & .65 & .5357 & .07254 \\
\hline \multirow[t]{2}{*}{ Laos } & $\begin{array}{l}\text { Total mark of } \\
\text { mental } \\
\text { adaptation }\end{array}$ & 88 & 30 & 63 & 43.15 & 6.577 \\
\hline & $\begin{array}{l}\text { Depression } \\
\text { index }\end{array}$ & 88 & .38 & .79 & .5393 & .08221 \\
\hline
\end{tabular}

Table 2. Degree distribution of mental depression situations of international students in China from Thailand, Vietnam and Laos

\begin{tabular}{llll}
\hline $\begin{array}{l}\text { Depression } \\
\text { degree }\end{array}$ & $\begin{array}{l}\text { Thailand (Percentage } \\
\text { of occupation) }\end{array}$ & $\begin{array}{l}\text { Vietnam (Percentage } \\
\text { of occupation) }\end{array}$ & $\begin{array}{l}\text { Laos (Percentage of } \\
\text { occupation) }\end{array}$ \\
\hline $\begin{array}{l}\text { No depressive } \\
\text { symptom }\end{array}$ & $30.5 \%$ & $34.8 \%$ & $30.7 \%$ \\
\hline $\begin{array}{l}\text { Minor } \\
\text { depression }\end{array}$ & $51.6 \%$ & $46.1 \%$ & $50.0 \%$ \\
\hline $\begin{array}{l}\text { Medium } \\
\text { depression }\end{array}$ & $13.7 \%$ & $16.7 \%$ & $17 \%$ \\
\hline $\begin{array}{l}\text { Severe } \\
\text { depression }\end{array}$ & 0 & 0 & $2.3 \%$ \\
\hline
\end{tabular}

According to the evaluation criterion of depression index, Thai students have better mental adaptation situations, while Vietnamese students are the mediate and Laotian students have higher rate of depression.

\section{Conclusions and inspiration}

According to the evaluation criterion of depression index, Thai, Vietnamese and Laotian students are of minor depression. But we should set them as psychological problems prevention objects. Factors like age, study time, learning hierarchy and major have notable influence on international students' mental adaptation. Thai students have a relatively good situation, Vietnamese are in the middle and Laotian students' depression degree is relatively high. In combination with learning motivation analysis, Thai students have better mental adaptation situations, since they have instrumental motivation and integrative motivation. In the correlation test between intention of studying abroad and mental adaptation, the correlation between depression index and intention of 
studying abroad of Laotian students is notable, indicating that the depression degree has positive correlation with the motivation to study abroad.

In the comparison of social support source, students set families and friends as main confidants, which is the main social support of mental adaptation problems of international students. This shows the normal reflection and choice of cross-cultural communication, while other choices of helping sources are regionally different. Thai students select Chinese students and other foreign overseas students for help most. Vietnamese students select Chinese teachers for help most, while the choice of Laotian students is the most conservative and they choose the Laotian people in China for help.

Students' mental adaptation is the main basis of socio-cultural and academic adaptation. The results show that teachers and administrators of overseas students should pay more attention to Laotian students' mental adaptation problems, guide them to expand the communication space and enhance their mental adaptation abilities.

\section{Acknowledgment}

Fund program: the 12th Five-Year Plan of science of education in Yunnan Province in 2014. The project is "Comparative study of culture contact and cross-cultural adaptation of Thai, Vietnamese and Laotian students under the perspective of educational anthropology" (Project number: BD14002). Staged results of doctor scientific researching fund projects of Yunnan Normal University "the research on cross-cultural adaptation problems of students from southeast Asia”.

\section{References}

[1] Jia Xiaobo, The Nature and Mechanism of Mental Adaptation [J]. Journal of Tianjin Normal University (Social Science), 2001(1): 19-23.

[2] Qi Hua, Luu HonVu, A Study of the Cross-cultural Adaptation of Vietnamese Students in China [J]. Journal of Yunnan Normal University (Teaching and Research on Chinese as a Foreign Language),2012, 10(6): 70-77.

[3] Chen Hui, The Research in Behavioral Psychology of Foreign Students' Sociocultural Adaptation in China [J]. Journal of Beijing Normal University (Social Science Edition), 2003(6): 135-142.

[4] Li Danjie, Cross -cultural Psychosocial Adjustment of International Students in China and its Implications for Chinese Higher Institutions [J]. Journal of Yunnan Normal University (Humanities and Social Sciences), 2007, 39(5):49-51. 